\title{
Transformation of the Three-Phase Interlines During the Electrochemical Deoxidation of $\mathrm{TiO}_{2}$
}

\author{
Pingsheng Lai, Meilong Hu*, Zhengfeng Qu, Leizhang Gao, Chenguang Bai, Shengfu Zhang \\ College of Materials Science and Engineering, Chongqing University, Chongqing 400044, China \\ *E-mail: hml@cqu.edu.cn
}

doi: $10.20964 / 2018.05 .23$

Received: 28 December 2017 / Accepted: 6 March 2018 / Published: 10 April 2018

The deoxidation of $\mathrm{TiO}_{2}$ cathode in molten $\mathrm{CaCl}_{2}$ was studied at $900{ }^{\circ} \mathrm{C}$ and under $3.2 \mathrm{~V}$ for different time periods. Materials were characterized before and after electrolysis by scanning electron microscopy, X-ray energy dispersive spectroscopy, and X-ray diffraction. The results show that the deoxidation process invariably proceeded through several intermediate species and can be described as four steps. The formation of the interfaces, especially the three-phase interlines (3PI) between the formed intermediate species and its subsequent transformation during the deoxidation process, are discussed. These findings are compared to the previous typical 3PI model.

Keywords: three-phase interline, electrochemical deoxidation, titanium dioxide, calcium chloride

\section{$\underline{\text { FULL TEXT }}$}

(C) 2018 The Authors. Published by ESG (www.electrochemsci.org). This article is an open access article distributed under the terms and conditions of the Creative Commons Attribution license (http://creativecommons.org/licenses/by/4.0/). 